\title{
Saussure em (dis)Curso: história e recepção nos manuais de linguística brasileiros
}

\author{
Marco Antonio Almeida Ruiz ${ }^{*}$ \\ USP \\ Lígia Mara Boin Menossi de Araújo** \\ UFSCar \\ Recebido em: 28/04/2019 \\ Aceito em: 09/11/2019
}

Resumo: O Curso de Linguística Geral, de Saussure, pode ser entendido, neste artigo, como um acontecimento histórico marcante; fonte de inesgotáveis questionamentos, a obra tornouse um marco na constituição da ciência linguística do início do século XX. Tomando-o como mote de reflexão, observamos como se dá a sua recepção nos diferentes manuais de linguística brasileiros, em especial, na obra Princípios de Linguística Geral, de Mattoso Câmara. Nosso objetivo é propor uma primeira (re)leitura da recepção do Curso numa época bastante significativa para o processo de institucionalização da ciência linguística no Brasil, que produz o efeito de sentido de didatização.

Palavras-chave: CLG. Recepção brasileira. Acontecimento. Manuais de linguística brasileiros.

Abstract: The CLG can be understood as a remarkable historical event; a source of inexhaustible questions, the book became a milestone in the constitution of linguistic science of the early twentieth century. Taking it as a reflection, we observe how it is receive in the different Brazilian linguistic manuals, especially in the book Princípios de Linguística Geral, by Mattoso Câmara. Our objective is to propose a first (re) reading of the reception of the Course at a very significant time for the process of institutionalization of linguistic science in Brazil, which produces the effect of a sense of didatization.

Keywords: CLG. Brazilian reception. Event. Brazilians linguistics manuals.

Résumé: Le CLG peut être compris comme un événement historique remarquable; une source de questions inépuisables, l'ouvrage est devenu un jalon dans la constitution de la science linguistique du début du XXe siècle. En prenant cet ouvrage comme notre réflexion, nous observons comment il est reçu dans les différents manuels de linguistique brésiliennes, en particulier dans l'ouvrage Principes de Linguistique Générale de Mattoso Câmara. Notre objectif est de proposer une première (re) lecture de la réception du Cours à un moment très important pour le processus d'institutionnalisation de la science linguistique au Brésil, ce qui produit l'effet de sens de didatisation.

Mots-clés: CLG. Réception brésiliène. Evénement. Manuels de linguistique brésiliens. 


\section{Introdução}

É certo que hoje há muitas discussões em torno da obra póstuma de Ferdinand Saussure, o Curso de Linguística Geral', publicado em 1916. Para alguns leitores, trata-se de um pensamento inacabado, incompleto, organizado com base em anotações de seus alunos durante os cursos na Universidade de Genebra entre os anos de 1907 a 1911. Assim, falar dessa figura, tão ímpar, requer, muitas vezes, retomar esse acontecimento na história da linguística e buscar novos questionamentos em torno de sua emergência no contexto brasileiro, por exemplo.

Nesse caminho, Saussure e seu Curso tornam-se mais atuais do que nunca. Em uma de suas passagens, Ítalo Calvino, escritor italiano, escreveu: "um clássico é um livro que nunca terminou de dizer aquilo que tinha para dizer [...] quanto mais pensamos conhecer, por ouvir dizer, mais se revelam novos, inesperados e inéditos" (CALVINO, 1998, p. 12).

Como todo clássico, o Curso de Saussure tornou-se um "ponto de origem" que contribuiu para pensarmos quem somos e aonde chegamos nas ciências humanas. Ele é ponto nodal para compreendermos o que convencionou-se chamar de linguística moderna. Assim, suas ideias, no contexto do início do século XX, suscitaram uma verdadeira revolução no desenvolvimento da ciência linguística e contribuíram, de certo modo, para que se extrapolassem as margens desse campo para serem inspiradoras de uma "ciência piloto". De tal forma, "não há um só linguista hoje que não lhe deva algo. Não há uma só teoria geral que não mencione seu nome" (BENVENISTE, 2005, p. 34).

A partir do Curso, vimos à introdução de um pensamento inovador em uma época conflituosa, marcada pela intensa procura de uma origem comum das línguas e de sua prática comparativa. Ao voltarmos às conceituações teóricas saussurianas, podemos, pois, não somente fornecer novos fundamentos à ciência da linguagem, graças às diferentes leituras e narrativas promovidas atualmente em seu entorno, mas também contribuir para que um arcabouço seja fortificado, refletindo as novas

\footnotetext{
${ }_{1}$ Doravante, CLG ou Curso.
} 
considerações acerca dos manuscritos e dos anagramas e, ao mesmo tempo, pensar sobre a composição de diferentes Saussures.

A partir disso, considerando o papel do CLG no cenário da linguística, neste artigo, buscamos refletir e investigar a sua recepção no Brasil, isto é, como ele é (re)lido por alguns manuais de linguística brasileiros, em especial, por Mattoso Câmara Junior em sua obra, também mister, Princípios de Linguística Geral (PLG), cuja primeira edição é de 1941. Tal recepção será tratada a partir de um olhar discursivo, empreendendo as considerações teóricas acerca das noções de acontecimento discursivo e da narrativa do acontecimento, propostas por Jacques Guilhaumou (2009).

Mattoso Câmara Junior é considerado pioneiro nos estudos linguísticos brasileiros, pois foi responsável por implementar a Linguística nos currículos dos cursos de Letras à época dos anos 1938, na então Universidade do Distrito do Brasil. Sua formação, embebida por teóricos estrangeiros, acabou promovendo a influência de outros pensadores em sua forma de ciência, contribuindo, inicialmente, para a introdução de ideias e ideais advindos de outros cantos do mundo. Nesse sentido, seu papel foi bastante significativo na década de 1940, aliado a um conjunto de manuais de linguística que circularam no espaço brasileiro cujo objetivo era (re)ler os clássicos estrangeiros acerca da linguística para a composição de uma linguística dos trópicos.

Assim, a narrativa de Mattoso, em seus Princípios, tornou-se ponto de vista responsável por produzir novos acontecimentos discursivos em torno de um acontecimento histórico, a publicação do Curso em 1916. Essa (re)interpretação será responsável por criar diferentes efeitos de sentidos a partir das diferentes narrativas que o (re)contam e o (re)significam por meio de novos acontecimentos discursivos, isto é, enunciados singulares que (re)configuram o acontecimento CLG no espaço brasileiro diferentemente. Diante desse cenário promissor, nossa hipótese de trabalho é a de que o modo como o Curso é recebido no país entre os anos de 1940 a 1960 especialmente no que tange ao ensino de linguística - pode coincidir com o processo de disciplinarização - a institucionalização da disciplina. Para tal, tomamos essa recepção do Curso enquanto um acontecimento de linguagem, narrado diferentemente em distintas narrativas dos manuais de linguística brasileiros da época, considerando as condições de produção da linguística no país a partir do surgimento desses materiais que, a sua maneira, constroem leituras particulares e singulares da obra póstuma de 
Saussure, produzindo, desse modo, novos efeitos de sentido: efeito de fundação, de disciplinarização, por exemplo². Para esta empreitada analítica, detemo-nos nos efeitos de sentido criados pela narrativa de Mattoso Câmara Junior em seus Princípios (1980, 5a edição).

Conforme já enunciamos, assumimos a concepção de acontecimento de Jacques Guilhaumou (2009), que se dá no interior do arquivo, isto é, considerado como algo que permanece reinterpretável juridicamente e, por conseguinte, atual ao próprio sentido. $\mathrm{O}$ arquivo, não é simplesmente um conjunto de textos que são produzidos e circulam na sociedade, como práticas documentais, é composto por saberes que se constituem ao longo dos tempos, nas mais distintas formações sociais, e que se articulam por meio de gestos de leitura que atualizam as configurações significantes, os dispositivos de significações de enunciados atestados (GUILHAUMOU, 2009). Assim, o arquivo não pode ser descrito em sua totalidade, mas se dá a ler por fragmentos de enunciados que se configuram em novas instâncias de enunciação e têm por consequência o surgimento de novos acontecimentos discursivos.

Nesse caminho, poderíamos pensar num acontecimento CLG - enquanto acontecimento histórico - sendo (re)produzido, (re)contado, (re)visitado por estes materiais que configuram uma recepção um tanto quanto peculiar, pois, associados ao gênero "manual", têm como principal característica a simplificação de certas conceituações teóricas e, com isso, assumem uma configuração de ordem didática. Em outras palavras, os manuais têm como objetivo primeiro instruir, de forma clara, sobre determinados conceitos teóricos, passando-os didaticamente ${ }^{3}$. Nesse processo de

\footnotetext{
2 Durante o processo de disciplinarização da linguística no Brasil, vimos o aparecimento de diferentes manuais de linguística representando diferentes pontos de vista adotados para a (res)significação do CLG. Cada narrativa, a seu modo, tomou determinados segmentos do Curso - restringindo-se às famosas dicotomias saussurianas - para a sua difusão nos diferentes contextos universitários. Podemos encontrar alguns dos principais manuais de linguística que figuraram durante este momento de institucionalização da linguística, a saber: Princípios de Linguística Geral (1941) de Mattoso, Fundamentos da Linguística Contemporânea (1976) de Edward Lopes e, Para compreender Saussure (1976), de Castelar de Carvalho, entre outros.

${ }^{3}$ É interessante notarmos que a forma como as narrativas dos manuais se configuram corroboram numa (re)leitura vulgarizada das ideias do CLG, isto é, em suas concepções, vemos apenas as dicotomias saussurianas sendo representadas como verdades incontestáveis sem, contudo, levantar os questionamentos em torno da autoria do CLG. Assim, observamos nos materiais a (des)construção de um Saussure e de um Curso: um material capaz de transmitir a imagem de uma obra "acabada", sem dúvidas. Não se trata, neste nosso artigo, de fazer determinados juízos de valores acerca desses materiais, pelo contrário, observar quais foram (e ainda são!) as condições de produção que contribuíram para que certos conceitos - as dicotomias, sobretudo - ganhassem
} 
didatização, muitas vezes, cria-se uma nova significação dos conceitos, já que ocorre um processo de simplificação e generalização, produzindo, dessa forma, novos sentidos. Se pensarmos tais considerações nas leituras do CLG elaboradas pelos manuais, teríamos, assim, a delimitação de um pensamento um tanto complexo e bastante discutido devido à natureza da produção editorial da obra.

\title{
Da recepção na França às (re)leituras do Brasil: caminhos para a fundação da
} linguística brasileira

À época de sua publicação, o CLG não assumiu um lugar de destaque entre os estudiosos. Sua circulação e seu reconhecimento se deu, especificamente, após a segunda guerra mundial e de múltiplos desvios geográficos e disciplinares, conhecidos pelos círculos de Praga, Copenhague, Nova York e outras áreas, tais como a antropologia, a sociologia e a filosofia, por exemplo. Pode-se dizer que o Curso é valorizado na França de forma ao mesmo tempo intensa, retrospectiva e paradoxal, como a fonte de um novo modo de pensamento (PUECH, 2011). Era um momento delicado da chamada linguística moderna implementada pela obra de Saussure, o estruturalismo linguístico começava a ser recebido e descoberto, todavia, ao mesmo tempo, já apresentava alguns sinais de esgotamento no final dos anos sessenta. Consoante Puech (2011):

\begin{abstract}
Nesse mesmo período, a semiótica (ou semiologia) apareceu sob o duplo aspecto de um campo de pesquisa científica em que novos objetos empíricos puderam ser incorporados (os debates entre Greimas, Barthes, Buyssens, Priéto e a antropologia estrutural de C. Lévi-Strauss) e, ao mesmo tempo, como uma investigação de caráter geral, propícia para questionar as tradições filosóficas então dominantes (a fenomenologia, o existencialismo, um certo marxismo, um freudismo cristalizado como ortodoxia) ou mais antigas (a filosofia transcendental de Kant a Husserl, o espiritualismo francês do século XIX...) (PUECH, 2011, p. 21).
\end{abstract}

Tal era a complexidade da situação que T. Pavel - um dos comentadores contemporâneos mais bem informados sob o período - descreve em 1988 a justaposição nos anos de 1960/1970 na França de três “espécies” de estruturalismo. Para

bastante força nos manuais e outros não, diante de um cenário de institucionalização da linguística no Brasil. 
ele, haveria um estruturalismo "científico" do qual destacam-se os trabalhos de C. LéviStrauss e A. Greimas. Tal vertente desenvolveu-se pela Escola de Semiótica de Paris e discutida por filósofos da linguagem que propunham projetos no âmbito da filosofia da linguagem, como, por exemplo, de H. Parret. A segunda vertente do estruturalismo refere-se a um período "moderado", que tomando as características da primeira versão, centram-se sobre as problemáticas literárias tradicionais, as quais procuram se renovar e proporcionar trabalhos sobre a morfologia da cultura, da estilística e da estética formalistas dos trabalhos do leste da Europa. Tais fatos não fornecem um conhecimento muito preciso sobre as condições de emergência, não contribuindo para uma visão desenvolvida. E, por fim, um estruturalismo “especulativo", cuja relação com as duas primeiras versões precedentes são reais, mas difusas, e cujo intuito é uma reavaliação completa dos desafios tradicionais em torno da reflexão (PUECH, 2011, p. 22-23).

Sob esse prisma, para compreender esse processo de recepção do pensamento saussuriano, inicialmente na França, mobilizamos algumas considerações teóricas de Christian Puech (2011), em que o autor trata o tema como algo novo. Revisitando algumas de suas considerações sobre tal temática, podemos observar que ele organiza tal recepção saussuriana em quatro fases principais. A primeira delas se constitui num momento no qual a obra não foi considerada fundamental e de forte impacto na comunidade linguística da época, ou seja, em solo francófono o modo de ler e a recepção de seu texto não foi imediata diante de seus contemporâneos, fato este que será retomado a partir dos anos de 1950. Diante desse cenário, surgiram resenhas sobre a obra saussuriana, trazendo como principal argumento o fato de que o livro continha em suas linhas uma perversão do real pensamento do mestre genebrino, dado o fato de ser uma publicação polêmica organizada a partir das notas dos alunos que frequentaram seus cursos na Universidade de Genebra entre 1907 a 1911.

Já em relação à segunda fase, o linguista francês relembra a influência da linguística dos círculos, mais especificamente, a partir do primeiro Congresso Internacional de Linguistas à La Haye, em 1928. É com a publicação do artigo de Greimas, na revista de linguística Le français moderne em 1956, intitulado L'actualité du saussurisme, que se tem um indício, discreto e eloquente, da instalação de um saussurismo francês. De acordo com esse artigo, os pressupostos de Saussure na época 
eram considerados um potente fator de "modernização" da cena cultural e científica francesa. Para Puech (2011), "trata-se de instalar Saussure na fonte e no horizonte de um projeto que mobiliza todos os saberes em renovação de sua época” (p. 39). Nesse momento, o CLG é considerado como uma edição portadora da novidade, obra que não era mais considerada "marginal" aos pressupostos saussurianos propostos no início do século XX:

Se não houve propriamente uma "recepção" de Saussure na França nos anos 20, vemos de fato constituir-se tardiamente uma "herança" nos anos 50, como se Saussure tivesse desempenhado o papel de uma origem adormecida, e como se seu "despertar" constituísse, na aurora dos anos 6o, um desafio de pensamento de primeiro plano, para pensar um novo regime do sujeito, da história, do simbólico, noções então entendidas em sua máxima extensão. A sequência do texto L'actualité du saussurisme confirma esse ponto, indicando uma teoria da cultura com a qual a França até então havia se preocupado muito pouco [...], sobretudo se compararmos com a situação alemã quando, nos anos 20 (PUECH, 2011, p. 36, itálico nosso).

A terceira recepção coincide com o surgimento da análise do discurso na França a partir das influências de Michel Pêcheux, em 1969, com o conceito de discurso, (re)formatado a partir das reflexões de Michel Foucault d' A ordem do discurso. Assim, o Curso adquire uma nova importância frente aos estudos linguísticos. Nesse momento, havia a proposta de organização de uma ciência linguística considerando-a como algo fundamentalmente científica. E, por fim, o autor aborda a última fase das recepções saussurianas, o que ele considera estar embasada nos trabalhos de Robert Godel sobre as fontes manuscritas do CLG (1967) e com a edição crítica de Rudolf Engler, uma edição cujo objetivo é comparar o texto do livro de 1916 com as notas dos cadernos de estudantes e rascunhos do próprio Saussure:

O saussurismo francês, pelo fato de seu nascimento tardio, é enfim uma referência indireta a Saussure, restituído por meio de toda uma série de prismas, um saussurismo por intermediação e transitividade das referências (Hjelmslev, Jakobson, Martinet, Lévi-Strauss) e por conversão brutal de atitudes intelectuais. Não se trata então de uma Escola ou de um Círculo (como se conheceu em Praga, Moscou, Copenhague), mas de uma "tendência", de um "movimento" multiforme que hesitará por essa razão em se reconhecer em si mesmo, mas que experimenta vivamente a necessidade de um limite de memória, de uma origem que não é em si mesma referida (PUECH, 2011, p. 40). 
Com efeito, o que pode-se ver sobre Saussure é um "limiar de cientificidade" que sempre é retomado, analisado, estendido, revisitado, fato que explica, por um lado, a pouca atenção dada aos manuscritos originais saussurianos e, por outro, a exposição crítica dos conceitos que lhe são atribuídos no contexto universitário francês.

Fazermos um paralelo entre Brasil e França, de certo modo, pode tornar-se um modo injusto, dadas as diferentes condições históricas de produção de conhecimento de ambos os países. Todavia, em se tratando da linguística saussuriana, a sua recepção no cenário brasileiro se dá, inicialmente, muito timidamente nos manuais de linguística a fim de evidenciar a sua introdução, por meio dos conceitos básicos de dicotomias ${ }^{4}$, nos diferentes cursos de Letras da época. Em nossa leitura, Saussure e seu Curso são trazidos em meio ao processo de institucionalização da linguística no país em que havia a necessidade de didatizá-la e representá-la como empreendida pelos autores clássicos estrangeiros, sobretudo da França. Conhecemos, assim, nesse primeiro caminho de interpretação de sua recepção brasileira, um CLG mais didatizado e "acessível", próprio para o contexto da época. A partir da leitura de Mattoso Câmara, esses clássicos autores europeus serão (res)significados no contexto brasileiro a fim de promover tal processo de didatização.

Nesse sentido, a década de sessenta no Brasil é considerada como um momento de intensos desdobramentos em torno de uma ciência que buscava se firmar e se institucionalizar, coincidindo com a terceira fase de recepção saussuriana no contexto francês. Enquanto lá, víamos as questões impostas ao método estruturalista (herdado do pensamento de Saussure) e a forma como questioná-las, sobretudo, pela influência da análise do discurso proposta por Michel Pêcheux (e o seu corte saussuriano), no Brasil, o estruturalismo adquire um impacto enorme, caracterizando-o como uma escola dominante e, ao mesmo tempo, corrobora com o reconhecimento da linguística como uma disciplina autônoma, atraindo muitos estudiosos pela nova orientação.

\footnotetext{
${ }^{4}$ Os clássicos manuais de linguística desenvolvidos no período - Princípios de Linguística Geral (1941) de Mattoso, Fundamentos da Linguística Contemporânea (1976) de Edward Lopes e, Para compreender Saussure (1976) de Castelar de Carvalho, entre outros - abordaram, de diferentes formas as principais dicotomias saussurianas, tais como significante vs. significado; sincronia vs. diacronia; sintagma vs. paradigma; língua vs. fala. Alguns mais, outros menos, a partir de suas narrativas, foram responsáveis por criarem diferentes efeitos de sentido acerca da recepção de Saussure no Brasil, a saber: de fundação, nos Princípios, de didatização, nos Fundamentos, entre outros. Cf. RUIZ, 2015.
} 
Assim, para a emergência de uma disciplina linguística que se pretendeu autônoma, fez-se necessário distinguir-se da Filologia e Dialetologia, tradicionais da época. Houve significativas mudanças na maneira de pensar os problemas, e no tratamento do objeto de análise - a língua(gem) - seja na concepção da carreira universitária seja na profissionalização do linguista. Com a disciplina instaurada, houve uma mudança no quadro profissional e, desse modo, grupos de especialidades se formaram.

Nesse sentido, tratar da história da linguística no contexto brasileiro é não partir apenas da compilação de datas, fatos, títulos e nomes relacionados ao estudo das línguas e da linguagem. Mais do que isso, é verificar no tempo quais foram as condições de seu surgimento e as relações que mantinham com os estudos que se voltavam à língua na época. A historiografia não depende apenas da composição de crônicas, listas de nomes ou datas, mas consiste, segundo Altman (1998):

Em uma atividade que ambiciona compreender os movimentos em história da ciência, que presume uma atividade de seleção, ordenação, reconstrução e interpretação dos fatos relevantes para o quadro de reflexão que constrói o historiógrafo (ALTMAN, 1998, p.24).

O que existe hoje na literatura da linguística no Brasil é bastante diverso. Podese dizer que não há muitas obras de referência que possibilitem recuperar, no interior de um arquivo, de forma sistemática e segura, a produção linguística brasileira como um todo ${ }^{5}$. Verifica-se, pela recuperação e reconstrução dos processos de cientifização e institucionalização dos estudos linguísticos brasileiros, que tais movimentos começam a delinear-se a partir da década de trinta. Por meio de um intenso processo de garimpagem em anais de congressos, em prefácios de traduções e de uns poucos textos que se produziam em ocasiões específicas, constatou-se que os autores estavam muito mais preocupados, inicialmente, em informar sobre os fatos e o que estava acontecendo na época, do que refletir criticamente a produção. Muito do que se produziu de material foi levantado de forma não sistemática e organizado a partir de critérios variáveis. Com exceção, talvez, de Mattoso Câmara Junior, autor que apresenta uma reflexão sistemática e única.

\footnotetext{
${ }^{5}$ Encontramos uma apresentação sugestiva sobre a historiografia linguística no Brasil em: ALTMAN,
} Cristina. A pesquisa linguística no Brasil (1968-1988). São Paulo: Humanitas/FFLCH/USP, 1998. 
Com efeito, Mattoso Câmara tornou-se um grande representante dos estudos linguísticos brasileiros e pode-se tomar a década de quarenta como o momento de irrupção da linguística brasileira. Marcou-se como fundador e produziu inúmeros materiais com o objetivo de divulgar a linguística. Tendo em vista a sua grande contribuição no início e no desenvolvimento dessa ciência, uma gama de possibilidades para a abordagem de seu legado são possíveis, entretanto, optamos em fazer um recorte específico. Nos dedicaremos, pois, neste artigo, à leitura que ele faz dos conceitos de língua e fala propostos, inicialmente, no CLG, sendo (re)contados, narrados e (res)significados em seu manual Princípio de Linguística Geral (PLG) de $1940^{6}$.

Os Princípios foi o primeiro compêndio de teoria linguística publicado em língua portuguesa, livro que, segundo Silvio Elia (1976), cumpriu com o seu destino. A "sua aparência modesta não deixava de suspeitar o que de inovador e renovador dentro dele palpitava" (ELIA, 1976 apud CÂMARA JUNIOR, 198o, p. 5). Ademais, tratou-se:

[Da] primeira edição dos Princípios [que] revê, em especial, a influência da Escola Francesa e a das correntes europeias, de maneira geral. Meillet, Vendryès, Saussure, Grammont, Jespersen são os autores mais citados. Contudo, já ocorrem nomes de norte-americanos, como Bloomfield e Sapir, mais este do que aquele, o que é sintomático (ELIA, 1976 apud CÂMARA JUNIOR, 198o, p. 5).

A obra do linguista brasileiro representou um novo modelo de estudos sobre a língua portuguesa. Com base numa orientação estruturalista, sob a influência europeia dos estudos saussurianos do início do século XX, sua obra descritiva contribuiu decisivamente para uma mudança fundamental no ensino de Língua Portuguesa, cujo estudo sincrônico ganhou grande importância nos anos 1960, quando não se limitava mais aos textos literários, base de comentários e classificações gramaticais. A linguística ligou-se, inicialmente, a uma corrente epistemológica estruturalista, herança de Ferdinand de Saussure e o CLG do contexto francês. No Brasil, essa influência estruturalista é marcada pela figura de Mattoso Câmara e de Aryon Rodrigues. Nesse sentido, pode-se observar que em meados da década de sessenta

\footnotetext{
${ }^{6}$ A primeira edição dos Princípios de Linguística Geral, de Mattoso Câmara, é datado de 1941. Para este nosso artigo, empreendemos a quinta edição, de 1980.
} 
colocavam-se sob a designação de linguistas apenas aqueles chamados de estruturalistas.

Logo, o termo linguística surgiu no contexto brasileiro já ligado ao estruturalismo e a partir daí, no decorrer da década de sessenta, os universos de referência dos dois acontecimentos - Filologia7 e Linguística - começaram a se delinear e a se distinguir, justamente pelas oposições institucionais que se faziam cada vez mais nítidas. Desse modo, a linguística entrava com força nos cursos de graduação das faculdades de Letras ${ }^{8}$.

Assim, os manuais tornam-se materiais de investigação importantes, pois acabaram sendo objetos de divulgação muito difundidos entre os estudantes e pesquisadores nas universidades a partir de 1940. Tais manuais retratam uma pequena parte do CLG que está associada a uma ordem discursiva, isto é, está ligada a um discurso de didatização das teorias, cujo objetivo é apresentar àqueles que não são iniciados na ciência linguística, o que seria de "mais relevante" da obra, por exemplo. Nesse caminho, às lides da vulgarização científica se associaria a um trabalho complementar de divulgação científica, que permite que um público mais amplo e heterogêneo tenha acesso às informações que circulam no meio acadêmico. Abordar a vulgarização seria compreender um antes, não vulgarizado, e um depois, vulgarizado, que seria produto do primeiro.

Não pretendemos emitir juízo de valor quanto à contribuição dos manuais ainda hoje há muitos em circulação durante a formação acadêmica - mas considerar que, a seu modo, contribuem para a descrição e a construção de uma ciência linguística brasileira ao mostrar um "outro" do CLG, mais didatizado e "acessível". Apesar de retomar muito do que está explicitado no Curso, pode-se pensar na construção de um outro Saussure, diferente do Curso, dado o caráter de sua composição. Teríamos um Saussure didatizado que supostamente explicaria, de maneira mais simplificada e, se possível, de forma clara e direta, tudo o que o CLG não conseguiu em 1916.

\footnotetext{
7 Segundo Uchôa Cintra (1939 apud ALTMAN, 1998, p. 78), "a Filologia é o estudo completo comparativo, filosófico, literário, histórico das línguas (ou de uma língua) consideradas em seus princípios, nas relações existentes entre elas, nas leis fonéticas que presidem à formação dos vocabulários, na origem das suas raízes e das suas formas".

${ }^{8}$ Rodrigues, por exemplo, em Brasília, foi o responsável por montar um curso autônomo de linguística em nível de pós-graduação.
} 


\section{A divulgação da linguística no Brasil: a narrativa dos Princípios}

É preciso tecer, brevemente, algumas considerações sobre as condições de produção da linguística no Brasil ao longo das décadas de trinta e quarenta para a irrupção do acontecimento discursivo do PLG. A criação das primeiras Faculdades de Filosofia em São Paulo e no Rio de Janeiro, na década de trinta, possibilitou o fim do autodidatismo sobre os estudos de linguagem e, com isso, a carreira do profissional de Letras começou a ganhar destaque nesse cenário. Embora antes desse período fosse possível encontrar inúmeros trabalhos que buscavam compreender a língua portuguesa, a partir dos mirantes gramatical, histórico-dialetológico e da crítica textual, considera-se a década de quarenta como o momento de irrupção da Linguística Brasileira. Mattoso Câmara era um ilustre representante desses estudos, foi professor de linguística e responsável por questionar as perspectivas teóricas (gramaticais, histórico-dialetológico) da época.

Com a publicação de seus Princípios, em 1941, constitui-se efetivamente a linguística no Brasil, o que, a nosso ver, configura-se como um acontecimento discursivo. É por meio de seus estudos, entre outros autores, que se inicia o olhar sobre os pressupostos da obra de Saussure no país. No PLG9, há diversos comentários do autor a respeito dos pressupostos saussurianos, configurando um novo acontecimento discursivo, a partir de enunciados singulares, que (res)significam o acontecimento histórico do CLG e "traduzem" seus principais conceitos e dicotomias. A tal construção, indicia-se à construção do que seria esse acontecimento e o seu desenvolvimento nos anos posteriores.

Essa obra de Mattoso Câmara é composta pelas aulas de linguística que ministrou na Faculdade, publicadas, inicialmente, pela Revista de Cultura. Sua obra não se preocupou em mostrar uma teoria própria, ao contrário, dedicou-se a introduzir um modelo que representaria grandes mudanças na maneira de pensar o objeto linguagem. Assim, as contribuições do linguista consistiam em derivar ideias (e ideais)

${ }^{9}$ O PLG é considerado por nós como um manual de linguística, mesmo que alguns estudiosos não o considerem como tal. É composto por dezenove capítulos que trazem os conceitos mais gerais da então nova perspectiva de abordagem da língua: a estruturalista. Assim, com o objetivo de investigar suas considerações sobre os conceitos de língua e fala e, tendo em vista a importância desse manual no cenário da linguística brasileira, buscamos, com ele, abrir sendas e veredas que possam proporcionar novas discussões em torno da obra de Saussure. 
linguísticos da Europa e dos Estados Unidos e aplicá-los na descrição e interpretação do português. Tais condições levaram o trabalho de Câmara Junior a se tornar obra de fundação da linguística no cenário brasileiro e, ao mesmo tempo, de divulgação e propagação dessas teorias estrangeiras.

É possível verificar que a obra contempla a linguística e seu objeto, abarcando desde os tipos de fonemas (capítulo seis) até as leis fonéticas (capítulo dezesseis) e a classificação das línguas (capítulo dezenove). Com relação à figura de Saussure e os pressupostos teóricos presentes no Curso, mais especificamente, encontraremos tais contribuições no primeiro e no quarto capítulos da obra brasileira, ressaltando que neste último, há um tópico chamado "a teoria silábica de Saussure". Para este esboço de nossa análise, separamos apenas a narrativa construída a partir dos conceitos (e dicotomia) de língua e fala, observando como eles são lidos e apresentados pelo professor brasileiro.

No capítulo Linguística: seu objeto, Câmara Junior (1980) mostra inicialmente a diferença entre a linguagem humana e animal. Segundo ele, "pode-se inicialmente dizer que a LINGUÍSTICA é a ciência da linguagem" (CÂMARA JUNIOR, 1980, p. 15). Ele ainda assevera:

Com isso, circunscreve a nossa ciência no âmbito do reino animal. Deve-se, porém, dar um passo adiante e, distinguindo entre os brutos e o homem, restringir ao homem o conceito daquela linguagem cujo estudo é o objeto da linguística (CÂMARA JUNIOR, 1980, p. 15).

Mais adiante, ele dá início à descrição do conceito de língua e fala. Segundo o autor, toda a comunidade de homens serve-se "de um sistema de linguagem, ou língua, cuja propriedade essencial é a de ser representativa” (CÂMARA JUNIOR, 1980, p. 17). Além disso, Mattoso retoma o conceito de fala, mostrando que se refere a "um conjunto de emissões vocais significativas" (p. 19). Ainda que trate desses importantes conceitos desenvolvidos no CLG, tais como língua(gem) e fala, por exemplo, é possível observar que o linguista, em sua narrativa, não chega a citar tais princípios associandoos ao CLG. Após a apresentação desses dois conceitos, ele recorre à figura de Edward Sapir, na tentativa de "ampliar" o panorama sobre o conceito de fala. Desse modo, nas palavras de Câmara Junior (1980), Sapir diria que:

A linguagem em si mesma não é nem pode ser localizada de maneira definida, pois consiste numa relação simbólica toda peculiar, e fisiologicamente arbitrária, entre todos os elementos da nossa experiência, de um lado, e, de outro lado, certos elementos selecionados, localizados nas regiões auditiva, motriz etc., do cérebro e do sistema nervoso (SAPIR, 1921, p. 9 apud CÂMARA JUNIOR, 1980, p. 19-20). 
Essas considerações permitem-nos dizer que a narrativa de Mattoso, em vez de trazer especificamente e exclusivamente as contribuições do Curso de Saussure, tem a preocupação de mostrar as contribuições de outros pesquisadores que pensaram sobre o conceito de língua e fala em um outro momento. Trata-se, pois, de retomar tal conceito, por meio de novos acontecimentos de linguagem, e (res)significá-los a partir de outro gesto de leitura, configurando uma nova narrativa sobre o mestre genebrino e sua teoria. Até este momento da narrativa, o autor-narrador ${ }^{10}$ Mattoso Câmara não menciona a figura de Saussure e as contribuições do CLG.

Em um tópico chamado Língua e Discurso, desenvolvido na página 24 do manual, podemos notar pela primeira vez uma menção de Câmara Junior ao autor genebrino. Em um primeiro momento, observa-se que o emprego de discurso com relação ao conceito de fala no manual é muito recorrente. Em um excerto, podemos encontrar a seguinte afirmação: "para Saussure, a linguística propõe-se a estudar a língua; e nos discursos individuais, que considera e analisa, só lhe devem interessar os elementos vocais coletivos e a sua organização normal" (CÂMARA JUNIOR, 1980, p. 25).

Na visão do brasileiro, não há distinção entre o conceito de língua e discurso. Torna-se notório nessa parte do manual que, diferentemente dos conceitos de língua e fala como mostrados pelo CLG, Câmara Junior traz o conceito de fala enquanto discurso, indo além da interpretação feita por Saussure em sua obra póstuma, tratando-se, nesse momento, de um novo gesto de leitura em relação à obra. Há, também, nítidas influências de outros estudiosos que refletiam sobre o mesmo conceito à época.

A partir dessa premissa, é possível inferir uma primeira característica em nosso esboço de análise: pode-se dizer, com isso, que o PLG deixa clara a função de divulgação de uma nova ciência no Brasil. Fundamentado nesse novo modelo, diante das perspectivas que aqui coexistiam - filológica e dialetológica - Mattoso e sua obra são responsáveis por instaurar uma disciplina linguística no cenário brasílico.

${ }^{10}$ Essa categoria de análise - cunhada por nós - representa não somente o posicionamento enquanto "autor", aquele que organiza diferentes vozes e produz a história, mas também enquanto "narrador", aquele que participa "a seu modo", narra e descreve os fatos, produz julgamentos, avaliações e, principalmente, atribui aos enunciados diferentes gestos de interpretação, que produzem efeitos de sentido de verdade distintos. O autor-narrador torna-se, assim, autorizado a falar não apenas sobre o Curso, sobre Saussure, mas também, muitas vezes, "como Saussure". 
Mais adiante, em sua exposição teórica referente aos conceitos de língua e fala (ou discurso, conforme se configuram no material), outra diferença significativa recorrente, em relação ao CLG, é a introdução da noção de estilística associada ao conceito de fala. Em um excerto, o autor brasileiro ressalta que "a estilística é, em essência, a depreensão da emoção, sistematizada nos atos de linguagem, a qual lhes dá um valor estético ('sensação', ‘sentimento')”. Ademais, ele acrescenta que "ortodoxamente, dentro da doutrina de Saussure, a escola suíça do seu discípulo Charles Bally também focaliza a estilística, frisando os aspectos coletivos que nela se contêm” (CÂMARA JUNIOR, 1980, p. 27).

Neste momento, mais uma vez, é possível perceber na narrativa do brasileiro o aparecimento de outros estudiosos para corroborar sua fala. Vemos, a partir disso, a presença de Bally, editor do CLG, retomado por meio de seus estudos em torno da estilística. Essa é outra característica que distingue a obra do linguista brasileiro do livro de 1916, visto que nele não há a descrição do conceito de estilística. O estilo, ou a fala de cada indivíduo, é visto no Curso somente por seu caráter individual, em oposição ao caráter social da língua. Podemos observar no PLG:

A língua é, de maneira geral, coletiva; mas cada um de nós tem certas peculiaridades linguísticas, ou pelo menos preferências, e há assim, de certo modo, múltiplas línguas individuais, ou idioletos, de acordo com a nomenclatura linguística norte-americana (CÂMARA JUNIOR, 198o, p. 27).

Embora existam tais diferenças entre a narrativa de Mattoso e o CLG, é possível, também, observar algumas coincidências entre elas. A primeira é a compreensão do autor de que a língua é coletiva, reforçando a ideia do CLG. A segunda é a arbitrariedade do signo, noção que ele retoma e a qual acrescenta que tal caráter foi depreendido da língua "como sistema feito para a função representativa” (CÂMARA JUNIOR, 1980, p. 30). Assim, em um excerto bastante significativo, notamos grandes semelhanças e diferenças, tais como:

Cada ato de linguagem, ou DISCURSO, se fundamenta num sistema de REPRESENTAÇÃO linguística, que é a LÍNGUA, e também sistematiza os recursos linguísticos representativos para a MANIFESTAÇÃO PSÍQUICA e o APELO numa estruturação estética, que é o ESTILO. A língua é, primeiramente, coletiva; mas pode ter secundariamente peculiaridades individuais, constituindo o IDIOLETO. O estilo parte primeiramente de um impulso pessoal; mas há todo um conjunto de coincidências estilísticas na 
comunidade linguística, constituindo-se o estilo coletivo (CÂMARA JUNIOR, 1980, p. 28, destaques do autor).

Diante desses fatos levantados, podemos pensar que há duas instâncias enunciativas em torno do manual. A primeira delas seria o autor-narrador-Mattoso Câmara, enquanto produtor do material e enquanto enunciador e, a segunda, seria o co-enunciador desse manual, isto é, os pesquisadores e professores brasileiros, até então imersos numa tradição filológica-dialetológica, e capazes de compreender as novas influências europeias e norte-americanas. Nesse caminho, teríamos um Mattoso Câmara que instaura uma disciplina linguística e divulga as teorias que compõem essa nova forma de pensar a linguagem.

Além disso, podemos, também, pensar que essa narrativa do manual possibilitanos dizer que se produzem efeitos de sentido de fundação e/ou divulgação. A partir desse momento de divulgação, foi possível uma autonomia da linguística perante a tradição compreendida como filológica, por uma ruptura não apenas sócioinstitucional, mas também com o conhecimento anteriormente difundido. Em outras palavras, as considerações e contribuições de Mattoso para a linguística brasileira tornaram possível o desenvolvimento dessa disciplina enquanto ciência autônoma. Ele, com sua narrativa e seu gesto de leitura - corroborado pela emergência de um acontecimento discursivo irrompido em novas condições históricas e sociais de produção e circulação - instauraria uma linha de investigação reconhecida como sendo a Linguística de base estruturalista no Brasil.

\section{Considerações finais}

São, pois, os gestos de leituras brasileiras acerca do CLG o norte e o fio condutor desta nossa reflexão. Nesse sentido, nosso objetivo principal foi investigar a recepção do Curso de Linguística Geral no manual de linguística brasileiro produzido por Mattoso Câmara Junior, a saber: Princípios de Linguística Geral (1980, 5 a edição), a nosso ver, um importante acontecimento discursivo. Acreditamos, com isso, que além da obra publicada em 1916 há ainda muito a se dizer sobre F. de Saussure e seu Curso enquanto um verdadeiro clássico que nunca esgotou o que pretendia mostrar. Com o passar dos anos, novos enunciados são possíveis graças às suas contribuições que colocados a circular (res)significam, diferentemente, a obra. O CLG, a partir de seu 
contexto editorial de produção, permite que novas abordagens frutifiquem para que possam ser abordadas por meio de outros vieses.

Pensamos, assim, que tal recepção do CLG - enquanto um acontecimento - é regida por uma ordem, a da didatização, que se constrói nas diferentes narrativas do acontecimento, cujo foco é ensinar Saussure e o Curso aos estudantes de Letras e Linguística recorrendo às principais conceituações teóricas, em especial, as dicotomias saussurianas língua e fala, sintagma e paradigma, significante e significado, entre outras. Para nossa reflexão, tomamos, a priori, essa recepção como um acontecimento CLG, que nos manuais de linguística, de maneira geral, coincide com um momento na história: o processo de institucionalização da disciplina linguística no Brasil. A nosso ver, tais materiais, de certa maneira, contribuíram, também, para o fazer ciência da época, isto é, para a construção do processo de descrição, constituição e divulgação da ciência linguística em nosso país.

Desse modo, buscar na história certos acontecimentos não significa que esses não podem ser retomados e/ou trazidos para novas discussões. Retomar o passado pode levar a (res)significar os acontecimentos e produzir novos efeitos de sentido no presente, novas interpretações contadas por diferentes autores-narradores. Ademais, constatamos que muito do que os autores-narradores produziram sobre as reflexões de Saussure no Curso, especialmente sobre os conceitos de língua e fala, referem-se sempre, direta ou indiretamente, ao CLG, acontecimento histórico marcante. Logo, desse ponto de vista, organizar tais narrativas sobre novos acontecimentos discursivos a partir do CLG contribui para que os discursos produzidos por meio dos manuais retomem e reforcem o caráter estrutural da obra original.

Ao olharmos para a história, colocamo-nos constantemente em novas (res)significações de acontecimentos passados que ainda são recorrentes e importantes para a descrição de uma disciplina científica. $O$ modo que tomamos esses acontecimentos é o que definirá nossa busca - por vezes incessante - trazendo novas perspectivas de trabalho.

Com efeito, quando propomos retomar e falar do Curso (e até mesmo de Saussure), pensamos em revisitar uma parte da história da linguística, recontada a partir de novas condições de produção, novas narrativas que rememoram um dado acontecimento histórico marcante, em um tempo presente, configurando diferentes 
enunciados singulares que (res)significam o(s) acontecimento(s) discursivo(s) marcado(s) pelo(s) manual(is). Remontando às considerações de Santo Agostinho, podemos pensar o "passado como uma recordação do tempo presente" e com ele, sem hesitar, buscar novas interpretações, novas narrativas que contribuam para (in)definir, procurar os (d)efeitos e/os caminhos de desenvolvimento de uma ciência.

\section{Referências}

ALTMAN, Cristina. A pesquisa linguística no Brasil. São Paulo: Humanitas/FFLCH/USP, 1998. BENVENISTE, Émile. Problemas de Linguística Geral I. Campinas: Pontes, 2005.

CALVINO, Ítalo. Por que ler os clássicos. São Paulo: Companhia das Letras, 1998.

CÂMARA JUNIOR, Joaquim Mattoso. História da linguística. Petrópolis: Vozes, 1975.

CÂMARA JUNIOR, Joaquim Mattoso. Princípios de linguística geral. 5. ed. Rio de Janeiro: Padrão Livraria Editora, 1980.

CARVALHO, Castelar. Para compreender Saussure. Rio de Janeiro: Editora Rio, 1976.

GUILHAUMOU, Jean-Jacques. Linguística e história: percursos analíticos de acontecimentos discursivos. São Carlos: Pedro \& João Editores, 2009.

LOPES, Edward. Fundamentos da linguística contemporânea. 2o. ed. São Paulo: Cultrix, 2008.

PUECH, Christian. A emergência do paradigma semiótico-estrutural na França. In: SARGENTINI, V.; CURCINO, L.; PIOVEZANI, Carlos. (org.). Discurso, semiologia e história. São Carlos: Claraluz, 2011. p. 19-65.

RUIZ, Marco Antonio Almeida. A recepção do Curso de Linguística Geral nos manuais de linguística brasileiros: um acontecimento discursivo. 2015. 128f. Dissertação (Mestrado em Linguística) Universidade Federal de São Carlos, Departamento de Letras, São Carlos. 2015. Disponível em: https://repositorio.ufscar.br/handle/ufscar/5801. Acesso em: 28 abr. 2019.

SAUSSURE, Ferdinand. Curso de Línguistica Geral. Tradução de Antônio Chelini, José Paulo Paes e Izidoro Blikstein. São Paulo: Cultrix, 2012.

UCHÔA, Carlos Eduardo Falcão. Dispersos. Rio de Janeiro: Fundação Getúlio Vargas, 2004.

\footnotetext{
* Recém-doutor em Linguística pela Universidade Federal de São Carlos (2019) e doutor pelo Colégio Doutoral em Sociologia da École des Hautes Études en Sciences Sociales (EHESS) de Paris. Pós-doutorando em Psicologia pela Universidade de São Paulo.

${ }^{* *}$ Doutora em Linguística pela Universidade Federal de São Carlos e pós-doutoranda em Linguística pela mesma instituição, com financiamento da CAPES.
} 